\title{
COMUNICAÇÕES
}

\section{Ocorrência de Curvularia lunata e Curvularia eragrostidis em Tapeinochilus ananassae no Estado de Alagoas}

\author{
Daniela Cavalcanti de Medeiros Furtado ${ }^{1,2}$, Edna Peixoto da Rocha Amorim ${ }^{1,3}$, André Luiz Beserra Galvão ${ }^{1,2}$, Juliana \\ Paiva Carnaúba ${ }^{1,2}$, Marcos Nunes de Oliveira ${ }^{1,2}$
}

\begin{abstract}
${ }^{1}$ Laboratório de Fitopatologia da Universidade Federal de Alagoas, Centro de Ciências Agrárias CECA/UFAL, Rio Largo, AL, CEP57100-000. ${ }^{2}$ Mestrandos - Bolsita CAPES/ FAPEAL; ${ }^{3}$ Prof ${ }^{a}$ Adjunto- Depto. Fitotecnia e Fitossanidade, UFAL. e-mail: furtado_dcm@yahoo.com Autora para correspondência: Daniela Cavalcanti de Medeiros Furtado. Data de chegada: 21/11/2005. Aceito para publicação em: 17/07/2006.
\end{abstract}

O Tapeinochilus ananassae ou gengibre abacaxi, é uma planta da família Costaceae que se encontra entre as plantas ornamentais tropicais cultivadas por diversos produtores, porém o seu cultivo tem sido restringido principalmente devido o aparecimento de várias doenças, entre elas Curvularia lunata e Curvularia eragrostidis causando perdas severas na produção.

Em julho de 2005, em um campo de produção, no município de Rio Largo, em Alagoas, contatou-se a ocorrência de sintomas nas brácteas das inflorescências onde se observam lesões necróticas, que coalescem e evoluem para podridão generalizada da inflorescência de T. ananassae (figura 1A). O objetivo deste trabalho foi identificar o agente causal da podridão em inflorescências de T. ananassae.

Para o isolamento de C. lunata e C. eragrostidis empregou-se o meio de batata-dextrose-ágar (BDA), onde fragmentos de brácteas desinfetados foram incubados a $25^{\circ} \mathrm{C}$ em fotoperíodo de $12 / 12$ horas claro/escuro.

A patogenicidade do isolado foi efetuada em inflorescências previamente limpas e desinfestadas em hipoclorito de sódio. Discos de BDA contendo micélio dos patógenos foram inseridos em incisões efetuados nas brácteas das inflorescências. As testemunhas receberam discos de meio de cultura, utilizando-se a mesma metodologia. As plantas inoculadas e as testemunhas foram mantidas em câmara úmida por 72 horas, à temperatura ambiente.

As inflorescências inoculadas com os isolados de $C$. lunata e $C$. eragrostidis apresentaram sintomas de necrose das brácteas cinco dias após a inoculação. Enquanto as testemunhas permaneceram sadias. As culturas foram então reisoladas em meio BDA e observadas quanto à semelhança, confirmando-se a patogenicidade dos isolados.

A identificação do patógeno foi realizada, respectivamente, através de observações na morfologia e dimensão das estruturas reprodutivas. As dimensões das estruturas foram obtidas por meio de 100 observações das estruturas reprodutivas de cada patógeno.

Os conidióforos em C. eragrostidis e C. lunata se apresentaram escuros, septados, produzindo os conidiosporos simpodialmente. Os conidiosporos em C. eragrostidis (figura 1B), apresentavam-se escuros, retos, quatro células, septo central espesso, medindo 25$16,60 \times 15-8,3 \mu \mathrm{m}(\mathrm{X}=20,38 \times 10,62 \mu \mathrm{m})$, enquanto os conidiosporos em C. lunata (figura 1C), apresentavam-se escuros, curvo, quatro células, sendo uma delas maior e com um lado mais desenvolvido, apresentando certa curvatura nos conídios, medindo 33,20-24,9 $\mu \mathrm{m} \mathrm{x}$ $18,26-14,9 \mu \mathrm{m}(\mathrm{X}=29,88 \times 16,73 \mu \mathrm{m})$.

A ocorrência de C. lunata e C. eragrostidis em Tapeinochilus ananassae foi o primeiro relato no estado de Alagoas.
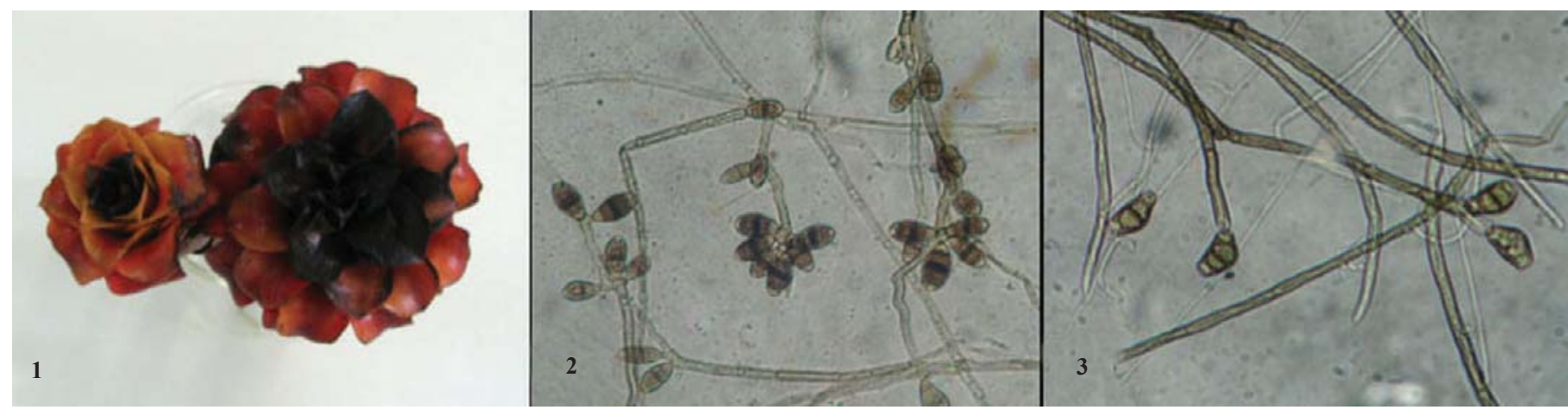

Figura 1. Sintomas de Curvularia sp. nas inflorescências de Tapeinochilus ananassae (A); conidiosporos de Curvularia eragrostidis (B); e conidiosporos de Curvularia lunata. 